\title{
The Pipeline: Preparing and Training Pulmonary Scientists for Research Careers
}

\author{
Herbert Y. Reynolds • Ann Rothgeb • \\ Sandra Colombini-Hatch · Dorothy B. Gail · \\ James P. Kiley
}

Published online: 8 October 2008

(C) Springer Science+Business Media, LLC 2008

\section{Erratum to: Lung}

\section{DOI 10.1007/s00408-008-9100-z}

Please note the following corrections to the above-mentioned article, published online on July 17, 2008. This article appears in the Sept/Oct 2008 issue of Lung (volume 186/no. 5, pp. 279 - 291).

Abstract: 1st column, line 21, "his" should be "this"

Page 281 (page 3 online): 1st column, line 6: "has" should be "had"
Page 285 (page 7 online): 2nd column, line 24: "11" should be "12"

Page 289 (page 11 online): 1st column, line 2 should be "90" not " 93 "; line 3 should be " 42 " not " 43 ", line 8 should be "90" not "93"

Page 290 (page 12 online): 1st column, line 8 should be "106" not "102"

Table 2: there were some column shifts which make reading the table difficult. The table is reproduced in full below:

The online version of the original article can be found under doi:10.1007/s00408-008-9100-z.

H. Y. Reynolds $(\bowtie) \cdot$ A. Rothgeb · S. Colombini-Hatch .

D. B. Gail · J. P. Kiley

Division of Lung Diseases, National Heart, Lung, and Blood Institute, Two Rockledge Center, 6701 Rockledge Drive,

Bethesda, MD 20892-7952, USA

e-mail: Reynoldh@nhlbi.nih.gov

H. Y. Reynolds · A. Rothgeb · S. Colombini-Hatch ·

D. B. Gail · J. P. Kiley

Department of Health and Human Services,

National Institutes of Health, Bethesda, MD, USA 


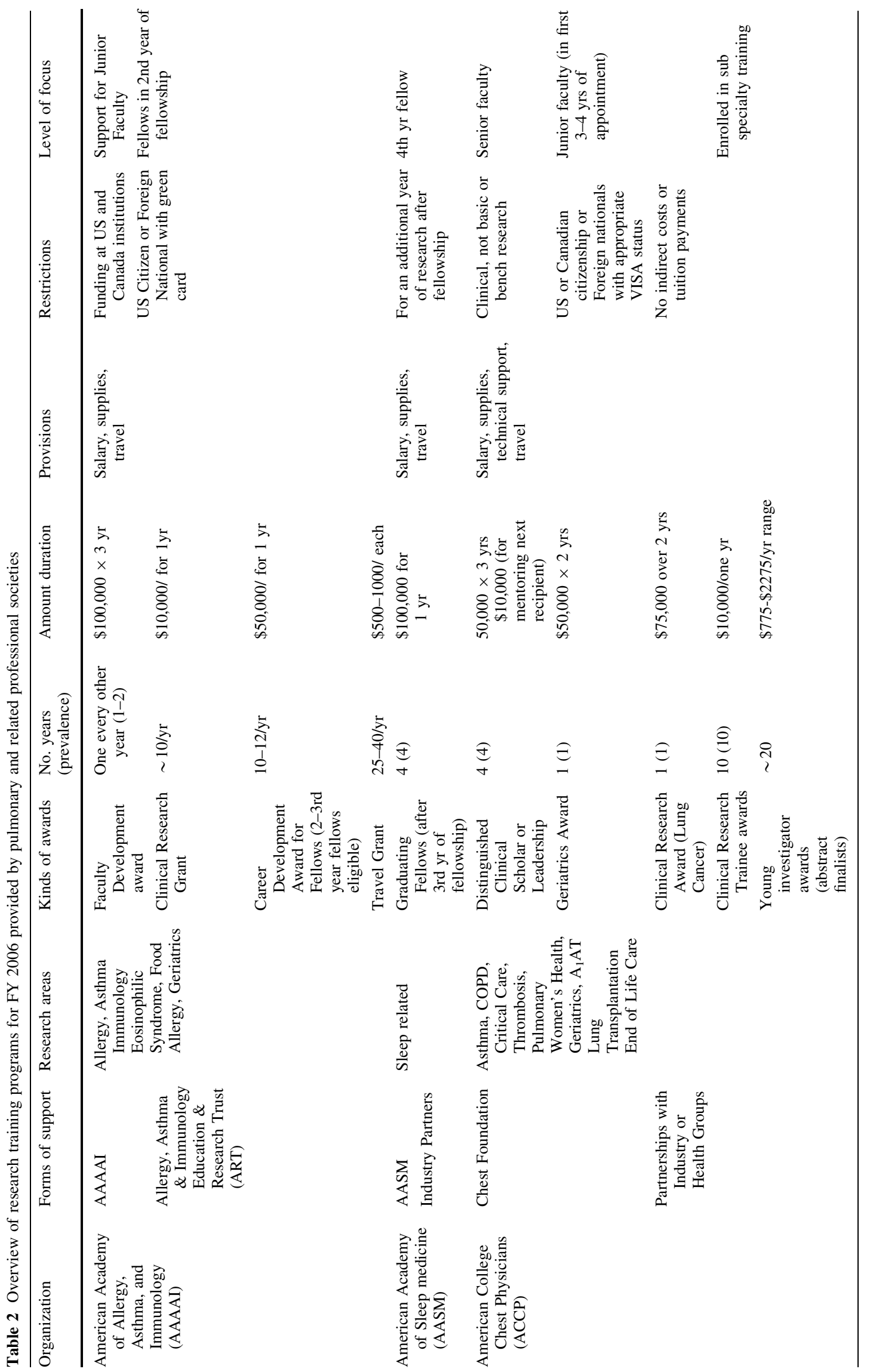




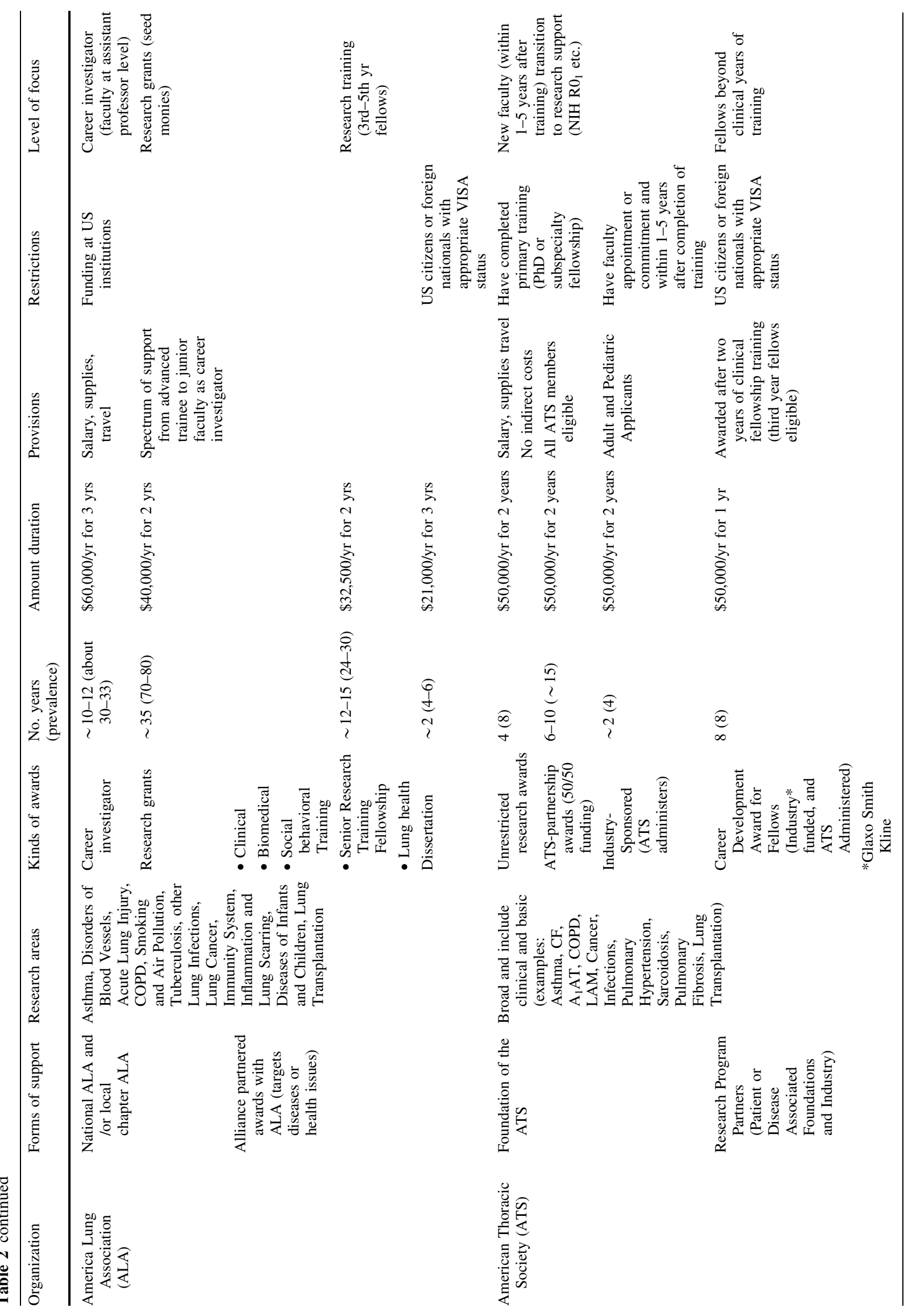




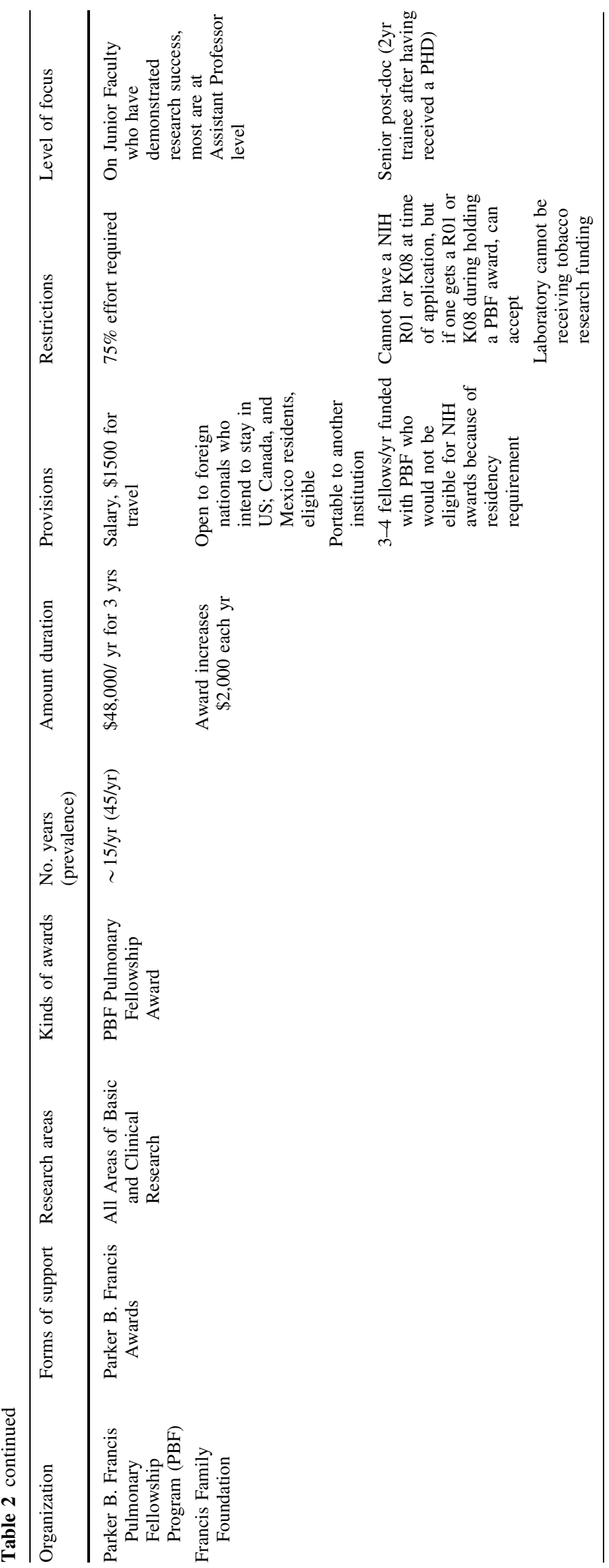

